\title{
In the Flesh: Living, Growing Conceptual Domains in a Geometry Lesson
}

\author{
A Response to Elizabeth Mowat \& Brent Davis
}

JENNIFER S. THOM, WOLFF-MICHAEL ROTH, AND ALFREDO BAUTISTA

University of Victoria (Canada)

\section{Offerings, Connections, and Occasions for Further Conversation}

It certainly is not a surprise that when we read and contemplate the ideas that Elizabeth Mowat and Brent Davis raise in their paper through their reinterpretation of mathematics that images of (co)evolving networks come to mind. The authors' paper, itself imagined as a discursive network offers and occasions several conceptual domains within which readers can explore the systemic, embodied, and metaphorical nature of mathematics as well as the consequent pedagogical implications that these ideas pose for mathematics teachers and learners.

Mowat and Davis move away from traditional images of mathematics and mathematical understanding by presenting a contrasting view through integrating theories of complexity science and embodiment. Identifying such characteristics as the nonlinear, recursive, dynamic, and diverse qualities of mathematics, the authors come to define it to be a complex system. Their discussion of the embodied nature of mathematics highlights the metaphorical ways in which patterns of inference are abstracted from physical experiences and give rise to conceptual domains. Bringing both of these theoretical perspectives together and utilizing network theory to explicate this integration, Mowat and Davis present a metaphoric network of mathematics in which conceptual domains function as nodes, conceptual metaphors serve as links between nodes, and when coupled, create a network of mathematical knowledge. The authors 
propose that imagining mathematics in this manner provides an alternative framework appropriate for gaining insight into the structure of mathematics and students' conceptual learning of mathematics in the classroom; particularly, in identifying source domains and conceptual metaphors that will increase the robustness and therefore, the stability of students' mathematics networks.

For us as individual researchers and a researching collective, we, like the authors, situate our inquiries within a theoretical orientation that views mathematical knowing and learning to be complex phenomena. More specifically, within Mowat and Davis' theoretical network there exist nodes through which our own evolving conceptualizations about mathematics education intersect. Located at the sites of mathematical concepts and conceptions but drawing on phenomenological accounts of knowing, our research conceives students' geometrical understandings as networks that function in a similar manner as characterized by Mowat and Davis; that when nodes are activated, they operate together in gestalt, creating a network which enables perceptions to arise.

However, in a subtly different way to the authors' image of conceptual networks as knowledge of and experiences with particular ideas that are held together by a central coordinating conceptual node, our ongoing inquiry into students' geometric understandings exposes a dialectical relationship whereby student conceptions and their embodied knowings as bodily experiences of realization each presuppose and constitute the other (e.g., Roth \& Thom, 2009). Briefly, we see two important implications here. First, by conceiving that "all doing is knowing and all knowing is doing" (Maturana \& Varela, 1987, p. 27) not only is the dialectic nature of knowing and doing elucidated, but at the same time, the very personal and contextually contingent qualities of these activities are revealed. Secondly, conceptions then, cannot be taken to be simply metaphorical extrapolations of bodily schema (themselves already forms of representation that are the result of deeper and more ancient processes) but instead, exist as such and possess the potential to provoke experiences that metonymically relate to the conception as a whole. Moreover, and this point is not often appreciated in the Anglo-Saxon literature, a phenomenological approach emphasizes not merely the role of the (material) body but in fact, the flesh, which is the living body that constitutes itself as material body (Henry, 2000). It is not therefore, that consciousness seeks and finds a body to become embodied. Rather, only a living body (flesh) can give rise - by means of processes of self-affection - to consciousness, subjectivity, knowledge, and so forth.

So, it is at these nodes of mathematical concepts and conceptions that we join Mowat and Davis' conversation and continue on by taking a phenomenological approach as we examine a videotaped episode of a geometry lesson for the emergence and growth of the students' conceptualizations. Our fundamental concern in reading the feature article and other studies in the field is with the potential they give rise to losing the human beings that we are in flesh and blood, with emotions and needs, anxieties and joys, that tend to be evacuated from any consideration what knowing mathematics is and can be. 


\section{Real People Doing Real Mathematics}

The following four sequential excerpts took place in a first and second grade classroom of 19 students in which one of the authors (Jennifer) designed and taught several lessons involving geometric concepts with the regular teacher. The previous day, the class sorted, according to the students' generated categories, a collection of objects that they had found around the classroom. The first episode that we selected from the videotape occurs just minutes into the lesson as one of the teachers (Jennifer) asks the class to review the categories that they used to sort the objects.

Excerpt \#1 (2:05 - 2:15)

Teacher: ... and we called this one here ([picks up a cardboard tube]), what did we call that group, ([looks to Teri who has raised her hand to respond]) Teri?

Teri: Circle.

Teacher: The circle group. That's right, we called it the circle group.

The lesson continues for several minutes as the students review the names and their reasons for the five categories in which the objects were sorted. Jennifer then returns to the circle group for further discussion.

\section{Excerpt \#2 (13:12 - 14:55)}

Teacher: We called this group the circle group, right? ([picks up the cardboard tube that the students placed in the group]), because we could see a circle here ([with her left hand, places a cardboard circle onto one end of the cardboard tube]), and if we turned it we could see a circle here ([places the circle on the other end of the tube]). That's what some of you said. But if somebody that wasn't here yesterday, was listening in our conversation and we were talking about the circle group, they might think we were talking about this, right? ([holds up the cardboard circle to the students]). Circles! But we want them to be able to think about all of this ([with a flat hand, fingers spread out and held in a horizontal position, she moves her hand from the base to the top of the tube]) (see Figure 1).

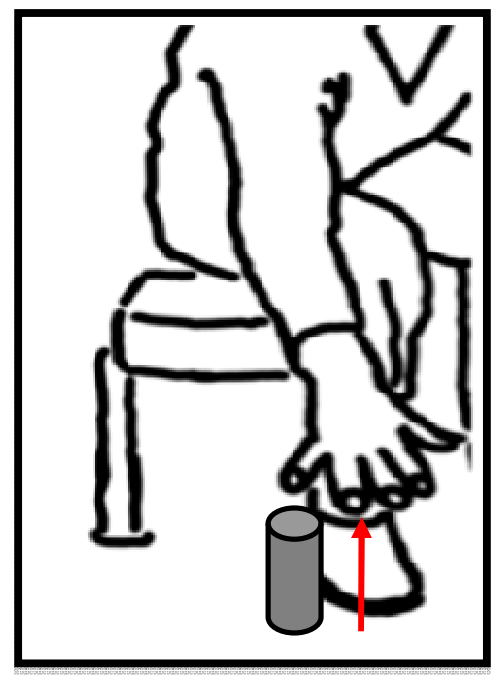

Figure 1: Teacher's hand gesture of the cardboard tube. 
Teacher: Can you talk to the people you were talking to before, and see if you can think of a name that would tell the person what this is, so that they don't just think of the flat circle, okay?

The students move back to work with their partner or small group. The students then engage in the following conversation:

Elisha: I think it could be a...

Jessica: ([Looks at the cardboard tube, turns to Elisha, and smiles]) Long circle ([looks back and forth at the tube and Elisha, repeatedly pointing at the tube]).

Elisha: Yeah, or a toilet circle because the toilet paper goes a--

Jessica: ([Giggles])

Michelle: ([looking at the tube and then back at Elisha and Jessica, interjects]) It is a toilet paper roll!

Elisha: Long circle? ([She then holds her arms out, bent in a $90^{\circ}$ position and shoulder width apart with her hands flat, fingers together, and palms facing inward]). Because it's this (see Figure 2).

Jessica and Michelle: ([look at Elisha as she does this])

Michelle: ([Looks at the cardboard tube for 6 seconds then turns back to Elisha and Jessica, and smiles]) Long circle?

Elisha: Yeah. ([Points to Jessica and nods her head several times]) Jessica said that.

Elisha: ([Looks to Jessica and Michelle]) (???) that?

Jessica and Michelle: (???)

Elisha: ([Raises her hand to respond to the class]).

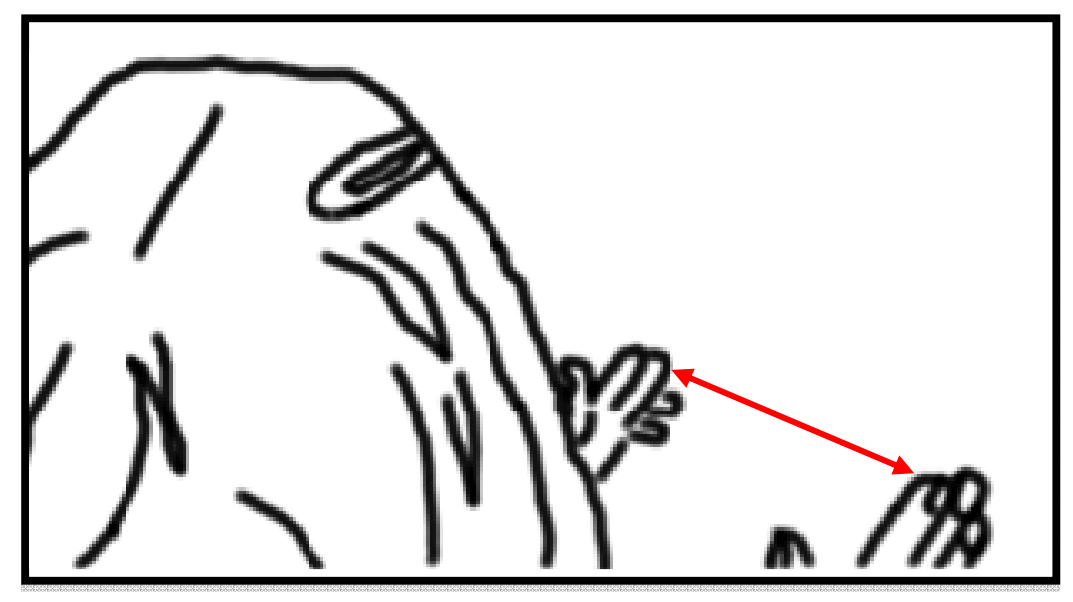

Figure 2: Elisha's hand gesture as she describes the cardboard tube as "long circle".

Not two minutes have passed when Jennifer brings the class back together and Elisha, Jessica, and Michelle share their name, "long circle," with the group. Jennifer then asks the rest of the class to share any other names that they have come up with. 
Excerpt \#3 (16:42 - 17:12)

Teacher: Did anybody have another name for this? ([shows the cardboard tube to the students]). Long circle is good... we wouldn't get it mixed up with the circle ([picks up the tube and moves her hands along the length of it twice, wraps both hands around it, and then looks to Nadia who is smiling and has her hand up]). Nadia?

Nadia: Round and round t-i-r-e circle ([holds her arms out bent in a $90^{\circ}$ position and shoulder width apart with her hands flat, fingers together, and palms facing inward, she moves her arms in unison several times up and down in a vertical circular fashion; her torso and head also move in unison and in sync with her arms, demonstrating the same circular motion]) (see Figure 3).

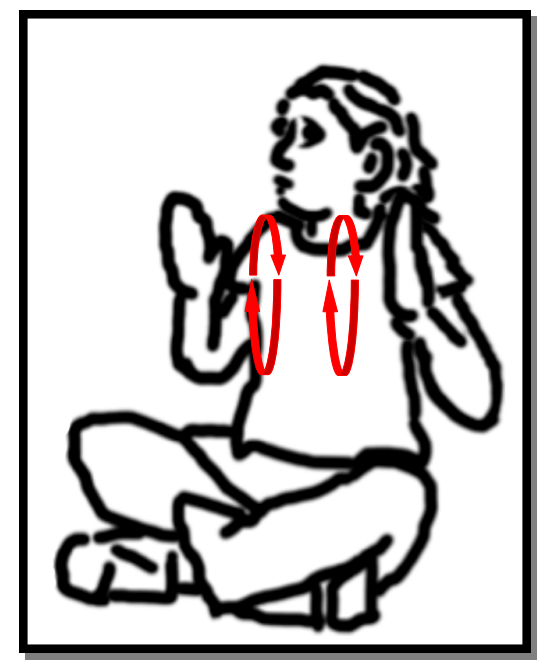

Figure 3: Nadia's circular arm, torso, and head movement for "round and round t-i-r-e circle".

Teacher: Okay. What does... round and round, and tire help us with, when we think about this ([shows the cardboard tube that is in her hands]), and not get it mixed up with the flat circle ([points to the circle sitting on the floor and holding her hands in a horizontal position, claps her hands together twice as she says, "flat"]) (see Figure 4).

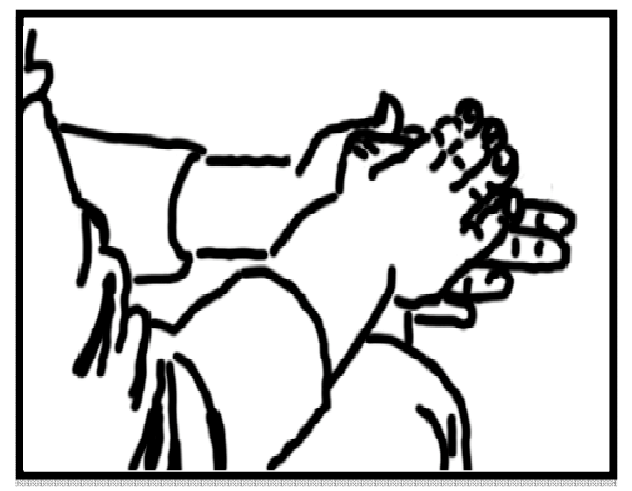

Figure 4: Teacher's hand gesture of clapping twice while saying, "flat" in reference to the circle. 
Nadia: ([takes the tube from the teacher]) Because it's just like a... thick, because it fits together and you can roll it!! (see Figure 5).

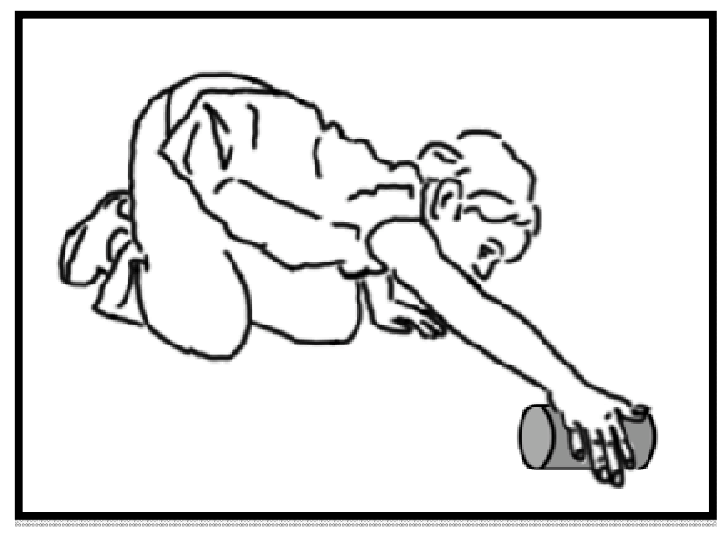

Figure 5: Nadia rolling the cardboard tube.

Teacher: It rolls. Okay!

Nadia: ([rolls the tube on the floor several times, by rolling it to her with her right hand, and rolling it away from her with her left hand]) Around and around.... It's not bumpy, like that ([tries, unsuccessfully, to roll a hexagonal prism]) it's r-o-u-n-d ([rolls the tube once again]) (see Figure 6).

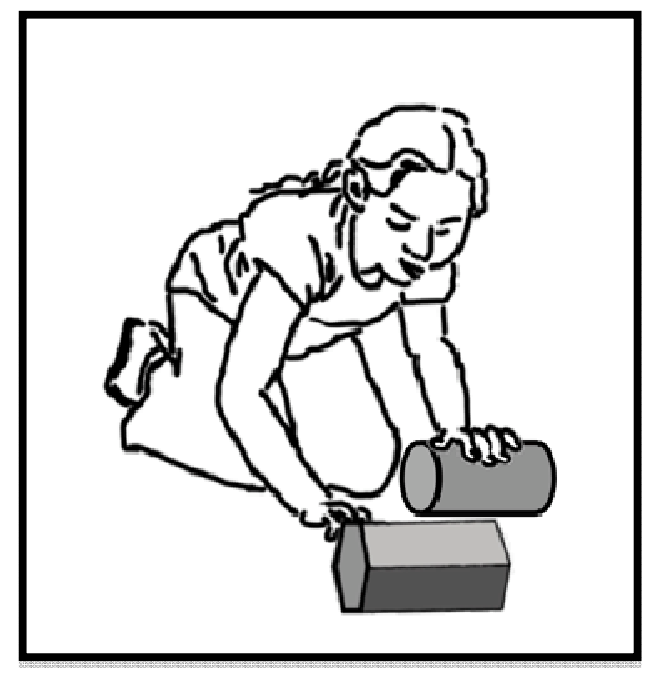

Figure 6: Nadia demonstrates that the hexagonal prism is "bumpy" and the tube is "r-o-u-n-d".

Teacher: The round makes it roll. Is that what you are saying, Nadia?

Nadia: Yeah ([still rolling the tube]).

Teacher: Thank you!

Nadia: Back and forth! 
Excerpt \#4 (17:16 -17:52)

Ken: I know another idea.

Teacher: Ken?

Ken: ... the towel circle?

Teacher: That's interesting that you said that because Arianne, you also said that too, ([looks at Owen]) didn't she? Remember when she said, paper towel? What were you thinking of when you said, towel circle? Were you thinking of a paper towel roll or a...?

Ken: Like a toilet paper roll ([cups his right hand slightly with the palm facing up and quickly moves his fingers one at a time in an upward curving motion]) (see Figure 7).

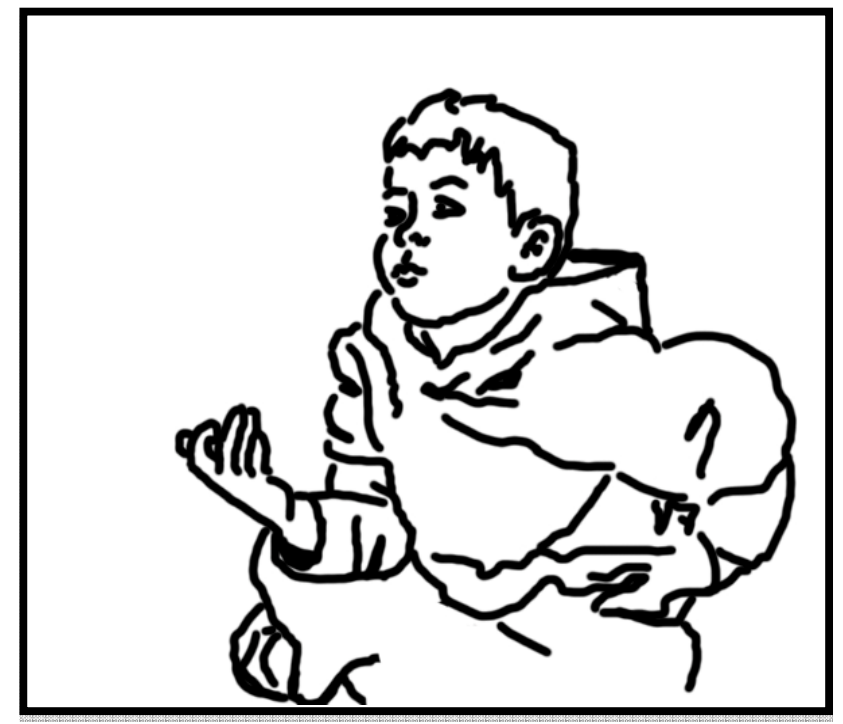

Figure 7: Ken's hand gesture that suggests the spinning of a roll of toilet paper in a dispenser.

\section{The Living Body and Mathematics}

Our analysis of the geometry lesson reveals three important insights that inform and deepen our understanding of the students' conceptualizations about geometry. These conceptualizations, in contrast to the Kantian idea, are expressions of and exist in the flesh, which is both the mode in which these expressions exist and the location where they exist. This flesh is endowed with a corporal memory that gives rise to intentional actions by doubling itself prior to any intentionality; intentionality presupposes the reminiscence of a power to act that has consequences, for example, in consubstantial sensations (Maine de Biran, 1952). Below, we discuss these insights as they pertain to the processes by which the children's understandings grew, particular events that unfolded during the lesson, and the nature of the students' conceptions. 


\section{Conceptualizing a Third Dimension}

The work done by the students in the four episodes documents their conceptualizations as beginning with the categorization of the cardboard tube as a two dimensional circle and eventually giving it a variety of names, all of which identify the object as possessing three dimensions. In Mowat and Davis's paper, the authors present three theorized processes by which new conceptual domains arise. These are: mapping (and discarding) features of one domain to another domain, the blending of concepts, and the use of a metaphor to enable new ideas.

There are six instances in the lesson where we observe the processes by which the students' conceptual transformations take place. Three somewhat similar transformations occur in the conversation that involves Elisha, Jessica, and Michelle. Jessica's suggestion that the new name for the category be "long circle", followed by Elisha repeating the name while gesturing -- holding the tube by its ends with her hands and Michelle repeating "long circle" after looking at the cardboard tube, all suggest the three students' recognition of the object as now having qualities of a circle and the dimension of length. Here, the students' new conceptions of the object are seen to be the result of their combining or blending of concepts related to circles and cylinders.

Other kinds of conceptual change are noticed as Nadia, Elisha, and Ken express them. In these instances, "circle" mediates their (and their partners or small group's) learning in a different way and differently for each of them. For these students, recategorizing the cardboard tube as "toilet circle", "round and round tire circle", and "towel circle" are not the result of the addition of a third dimension. Their learning arises from the ways in which the metaphorical and metonymic power that "circle" mediates their subsequent thinking. Nadia demonstrates a conception of "circle" which is available in and as of the articulation of the roundness of the cardboard tube and the image of a tire. This then leads to her distinction of the object as thick and, consequently, its ability to roll because it is "not bumpy" (as opposed to the hexagonal prism which is). In contrast, "circle" enables Elisha's perception of a toilet paper roll and around which the paper is wound. Further still, Ken shows that "circle" evokes the image of a roll of toilet paper in a dispenser and the action of unrolling it. Such images do not and cannot exist independently of the kinesthetic-sensible experiences of the situation as a whole, that is, of the living body (flesh) that is both the mode and the receiver of the donation of the image.

For these three students (and their partners or group, we assume, because these names emerged in their work together), we surmise "circle" as not something they use in a process by which they blend other concepts together or that which is taken to compare the cardboard tube against but instead, "circle" metonymically denotes their conceptions of circles, in and as of their embodied expressions and from which occasions the emergence of their other knowings and new names which hold both metaphorical and metonymical potentials. In these ways, we see the growth of their understandings evolve in a manner more closely aligned to the continual metaphorization that has led from the Greek mathematical understanding to the present day understanding, both as a cultural-historical and ontogenetic phenomenon. But for such a development to occur, 
mathematics has to have the potential to be relived each time it comes to be enacted and made present for oneself as much as for others. It is precisely the lived work of doing "knowing," "expressing," "metaphorizing," and "metonymizing" - a kind of work inseparable from emotions, affect, and everything else we feel in and with our bodies that tends to get lost in the abstractions of theory including the conceptual networks that the feature authors provide us with.

\section{Conceptual Change and the Emergence of Metaphors}

It is interesting and noteworthy that neither teacher introduces any metaphors to the students. However, in amongst Jennifer's gestures of moving her hand in an upwards motion and clapping twice to punctuate the flatness of the circle, it is the students themselves who contribute by making available to the rest of the class, several different names for the re-categorization of the cardboard tube. Like "circle", each of the names: long circle, toilet circle, toilet paper roll, round and round tire circle, paper towel, and towel circle serve both metaphoric and metonymic purposes for the students, revealing their comprehension of the object as being three dimensional and possessing cylindrical qualities. In fact, this production of names constitutes a displacement of signifiers in a chain of signification. Although all of these signifiers are thought to denote the same signified; that is, the same thought or idea, each signifier in fact grows and unfolds in and through the students' articulations. The continual displacement leads to a networking of signifiers, a constitution of the ideational relations that weave the increasingly dense (con)texture that constitutes and grounds what we can (and come to) know as the students' mathematical conceptions.

As evocative and provocative as these names are for the students as they work on the task and compelling for us as researchers because we can make direct observations about their spatial conceptions of the object, it is impossible to ignore how personally and contextually contingent the students' perceptions of the object are (as exhibited in their bodies, which constitute and are their thoughts, as there is nothing underlying and behind). None of the students refer to the cardboard tube as a cylinder. Rather, each of the categorical names can be seen on the videotape as emerging from very real, lived experiences. Even the class' original name, "circle", arises from their holding of and transacting with the found cylinders to locate the circles at their ends. The cardboard tube prompts Jessica's image of a long circle that then identifies the object for Elisha as a toilet circle, that later becomes known as a toilet paper roll for both Elisha and Michelle and finally, a long circle for all three students. Nadia and Deirdre's name, "round round tire circle" brings forth the experience of moving with a rolling tire. For Arianne and Owen, the cardboard tube now exists as a roll of paper towel, and for Ken and Trevor, it is a roll of toilet paper that for Ken (and possibly, for Trevor) is a roll of toilet paper that spins in a dispenser. Here spinning is not some abstract idea or process, it is a form of work that requires effort, which we sometimes do not want to expend! Each and every articulation made by the students in their work to re-categorize the cardboard tube is situated in and never removed from the contexts in which their knowings are grounded. 
Their conceptions exist in and as of their bodily expressions, that is, expressions of living, sensing, feeling, and sensing bodies that are constitutive of the sense they make and make available to each other.

\section{The Nature of the Students' Conceptions}

The excerpts from the geometry lesson not only exemplify the transformation of the students' categorical perception of the cardboard tube from a 2D circle to a 3D object but also expose the emergent nature by which these conceptions evolve. The students' understandings certainly are not pre-existent but in fact, are brought into being precisely in the moments at which the students articulate them. And it is in these instances of articulation that we as researchers realize the very bodily manner in which the students' further learning about the cardboard tube exists. With, through, and in the experiences of a hand gesture and clapping of the teacher, pointing to the object and visually distinguishing its length, touching and manipulating objects, and setting their bodies or other material objects into specific kinds of motion, the children recursively sense and make geometric sense of the tube. These are experiences of living rather than material bodies, auto-affecting and auto-affected flesh, filled with affect that gives shape to the students' engagement and perceptions. In this way, the children's final conceptions of the cardboard tube never become disconnected from their conceptions of "circle" but connect to (also evident in their chosen names of "long circle", "round and round tire circle", and "towel circle") and branch out into a network or conceptual domain of "cylinder". These are not disembodied, idealized, and ideological networks, these are experiences that are unified by the living body that gives rise to them, sustains them, and constitutes the very mode of remembering them; that is, the living body constitutes a deeper and more ancient memory that eventually gives rise to the representations that thought requires to operate upon the ideal and idealized entities commonly referred to as mathematical objects and processes.

\section{Toward a Mathematics in and of the Flesh}

We, the authors, began our discussions of Mowat and Davis' article with the acknowledgment that it reflects an approach that we empathize and affiliate with. But we would like to move the understanding of mathematics further, even further than talking about it as being embodied. The concept of the "body" does not make the phenomenologically important distinction between the material body (Ger. Körper, Fr. corps) and the living body, the flesh (Ger. Leib, Fr. chair). It is only the flesh that can sense, auto-affect, remember, and know. The flesh co-appears in and with anything that we can perceive and be conscious of. This flesh, however, becomes lost in our idealizations of networks that exist precisely when the flesh comes to be evacuated from our theories. And once evacuated, we also lose not only emotion but also its integration with thought such that it appears as if thoughts are thinking themselves rather than being the expression of a living body as an affected, affecting, and affectable expression of life itself. In fact, life can become conscious of itself only in and through the flesh; and 
it is only because of the needs experienced in and by the flesh that anything like an intention to know and learn can exist. We therefore argue for putting the flesh back into our theories so that mathematics and mathematical understandings find again, their natural and only mode of expression and location.

\section{References}

Henry, M. (2000). Incarnation: Une philosophie de la chair. Paris: Seuil.

Maine de Biran, P. 1952. Mémoire sur la décomposition de la pensée. Paris: Presses Universitaires de France.

Maturana, H., \& F. Varela. (1987). The tree of knowledge: The biological roots of human understanding. (El arbol del conocimiento, Trans.). Boston: Shambhala.

Roth, W.-M., \& J. S. Thom. (2009). Bodily experience and mathematical conceptions: From classical views to a phenomenological reconceptualization. Educational Studies in Mathematics 70 (2), 175189.

\section{Acknowledgments}

This research project was supported by a grant from the Social Sciences and Humanities Research Council of Canada.

\section{About the Authors}

Jennifer S. Thom is an assistant professor of mathematics education and curriculum studies in the Department of Curriculum and Instruction at the University of Victoria, Victoria, British Columbia. She can be contacted at the following email address: jethom@uvic.ca

Wolff-Michael Roth is the Lansdowne Professor of Applied Cognitive Science at the University of Victoria, Victoria, British Columbia. He can be contacted at the following email address: mroth@uvic.ca

Alfredo Bautista is a post-doctoral fellow who is working with the first two authors on the research project, Embodied Knowing and Learning in Elementary Mathematics. He can be contacted at the following email address: alfredo@uvic.ca

(C) Copyright 2010. The authors, JENNIFER S. THOM, W. MICHAEL ROTH, and ALFREDO BAUTISTA, assign to the University of Alberta and other educational and non-profit institutions a non-exclusive license to use this document for personal use and in courses of instruction provided that the article is used in full and this copyright statement is reproduced. The authors also grant a non-exclusive license to the University of Alberta to publish this document in full on the World Wide Web, and for the document to be published on mirrors on the World Wide Web. Any other usage is prohibited without the express permission of the authors. 